\title{
PATHOLOGICAL PRINCIPLES IN THE MANAGEMENT OF SPINAL CORD TRAUMA
}

\author{
By G. M. BedBrook, O.B.E., M.S., F.R.C.S., F.R.A.C.S. \\ Royal Perth Hospital, Perth, Western Australia
}

\begin{abstract}
ADEQUATE clinical judgment in medicine needs physicians who have a knowledge of morbid pathology, morbid physiology and human understanding. These basic concepts of medicine can now be applied to the management of spinal cord trauma. The accumulated evidence assembled by many in many countries shows that spinal cord trauma associated with cord damage has fundamental patterns which I shall attempt to summarise. Recently this subject has been reviewed fully by Wolman (1964) from Sheffield.
\end{abstract}

\section{ANATOMICAL}

I. Capacity. The spinal cord, as it occupies the neural canal, has a variable relationship to its bony cartilaginous container in regard to capacity. Thus it may vary from a large cord in a small canal to a small cord in a large canal. A reduction of up to 50 per cent. is frequently needed before the cord is in danger (Scarff, 1960). Such capacity variations play, I believe, a part in the subsequent course of traumatic incidents. Again, the cervical and lumbar enlargements of the cord occupying those parts of the canal which are most mobile and in themselves occupying a greater percentage of the spinal canal are more prone to accident.

2. The Pattern of the Spinal Cord Arteries and its Relation to Observed Pathological Features (Gillilan et al., 1962). Arterial blood enters the spinal cord by a number of ways:

Extrinsic Vessels. (a) The anterior spinal artery is formed above by the fusion of two branches from the terminal parts of the vertebral arteries. This vessel is not uniform in sections throughout its course, being greater at the cervical enlargement and greatest at the lumbar enlargement, where it is reinforced by medullary vessels.

(b) By constant medullary vessels at (i) the lumbar enlargement and (ii) the cervical cord. These medullary vessels, usually unpaired, enter via the nerve roots from the cervical and thoracic segmental vessels. cord.

(c) By direct vessels from the vertebral (at segmental levels) in the cervical

(d) Posterior spinal arteries which arise from the vertebral and thoracic segmental vessels and soon join with posterior medullary vessels to form posterior plexiform channels located in a line with the entrance of the posterior nerve roots.

(e) Of particular note are two large posterior medullary vessels that enter the lumbar enlargement. 
Intrinsic Arterial Pattern. (i) A centrifugal system of central vessels supplying mainly the central grey matter and the anterior two thirds of the spinal cord plexus.

(ii) A centripetal system of short, vertical vessels arising from the pial

These patterns must be remembered when considering the various syndromes that emerge in spinal cord trauma. The importance of associated arterial trauma and its secondary effect on the cord has been well recognised as the reason for extension of neurological deficit days after an accident, e.g. see papers by Barnes (I948), Wolman (1964) and Schneider et al. (1958).

Recently, Hughes (I964) from Oxford described two cases where vertebral artery insufficiency played a major part in myelopathy associated with acute cervical spine trauma. Thus in the management of such trauma every effort must be made to minimise such continuing stress as may cause further ischaemia, e.g. undue movement, variations in circulation, and initial shock. Wolman (1964) has summarised the literature and makes mention of these particular features. With such structural considerations in mind, it is not difficult to see how operative surgical decompression, no matter how carefully carried out, may interfere with the normal vascular pattern of the cord with subsequent severe myelopathy. Undoubtedly the cause of deterioration seen occasionally subsequent to even the best of surgical exploration is partly due to further interference with vascular supply of an already damaged area, e.g. the cervical and lumbar enlargements where constant radicular medullary vessels assume great importance.

3. Anatomical variations in the actual cord structure play a big part in the patterns of dysfunction that emerge. Consideration of cord anatomy and its normal variations show that the pattern of tract pathways can vary in regard to discreteness and position. Mixtures of upper motor neurone and lower motor neurone lesions are seen particularly in the cervical and lumbar enlargements of the cord where the proportion of grey tissue is always larger, thus the characteristic central syndrome of the cervical cord shows a mixture of lower motor neurone and upper motor neurone signs.

\section{PATHOGENESIS}

Turning to the various mechanisms by which trauma occurs, the following are of pathogenic importance:

$\left.\begin{array}{l}\text { I. Flexion } \\ \text { 2. Extension }\end{array}\right\}$ with or without: 3. Rotation

4. Vertical compression or dispersion.

Such external forces can usually be diagnosed at the time of original injury, for they each produce characteristic bony pathological patterns recognisable on $\mathrm{X}$-ray plates, and by careful clinical interrogation and examination of the patient. Their occurrence can be correlated with the internal neural pathology where extra mechanisms can be observed. 
5. Stretching of the cord

6. Crushing of the cord with or without: 7. Vascular disturbance

8. Concussion of neural tissue.

The pathological evidence for these latter will be examined later in this paper where they are at times only too apparent in those cases coming to post-mortem. Correlation between all these mechanisms show that flexion, extension and rotation injuries are frequently associated with crushing injuries to the cord which will remain complete, whilst vertical compression injuries are more often associated with incomplete lesions with haematomyelia. Such correlation pathologically is, I believe, difficult but essential in our consideration of the pathological principles governing therapy.

\section{MORBID PATTERNS}

Acute. I. Haematomyelia of the Cord. This is more commonly associated with a vertical compression or dispersion injury to a vertical body (Figs. I and 2). Such a lesion is clinically observed to be not infrequently incomplete, neural tissue being intact around the periphery of the damaged area. In a series of 4I such cases observed clinically in Australia, 30 were incomplete and I I were complete. The size and extent of such a lesion varied greatly from specimen to specimen in the post-mortem series, so that some are only a series of petechial haemorrhages while others are a definite central collection of fluid (blood). This latter thus giving rise to the central haemorrhage syndrome and partly to the anterior cord syndrome (as described by Schneider, I954). The mechanism by which such damage occurs is interesting to consider, for many, if not most, of the associated compression fractures are stable from the outset; gross macroscopic evidence of flexion injury infrequently existing (see Beatson, 1963). However, in its pathogenesis stretching and flexion undoubtedly have some part to play. Bearing in mind the vascular pattern already described it is not difficult to understand that there

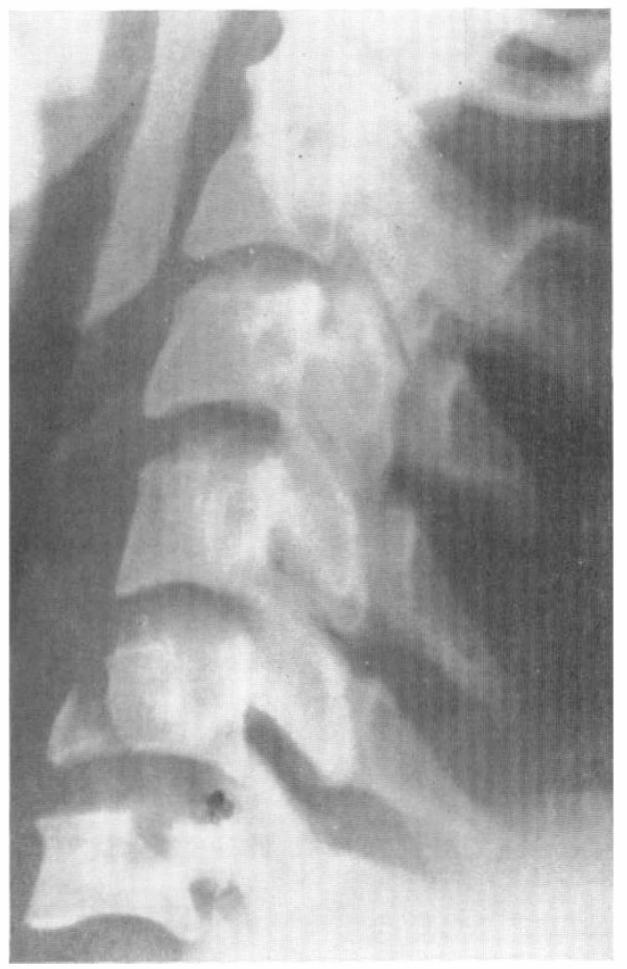

FIG. I

Vertical compression or dispersion fracture. 
is also a definite vascular factor in the final visible manifestation. Central haemorrhages are thus usually confined to the field of distribution of the central arteries How then does the arterial pattern become interfered with? The following are noteworthy:

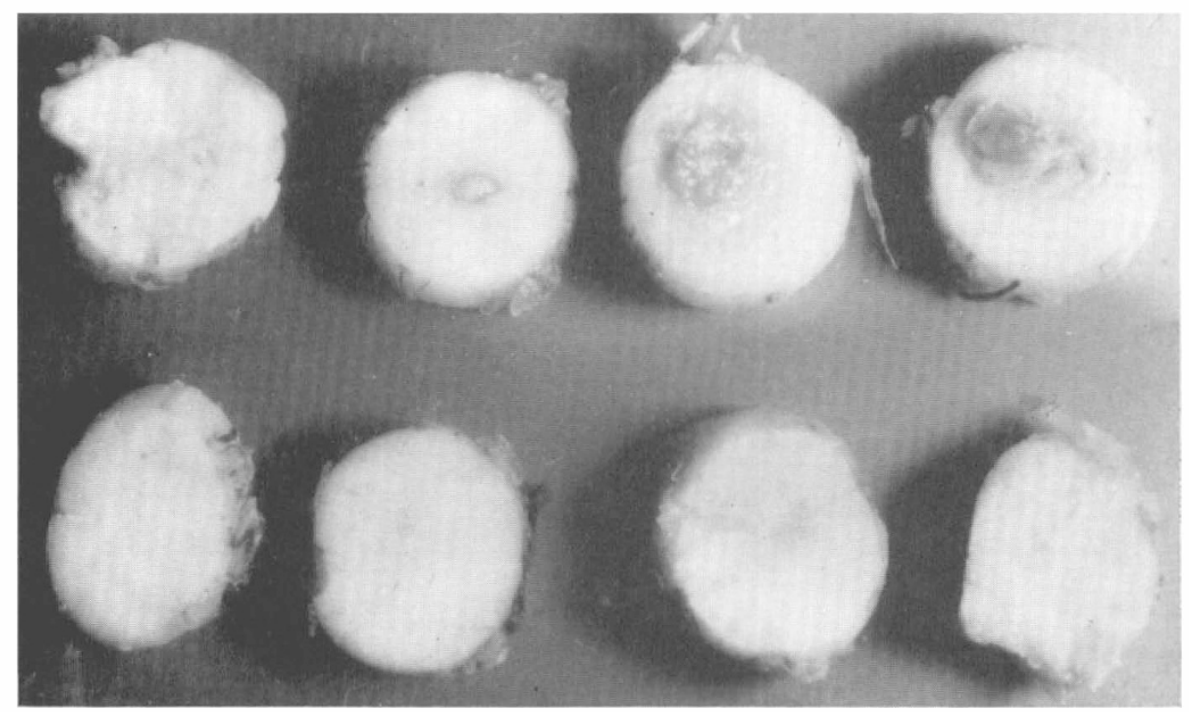

FIG. 2

Haematomyelia of the cord, incomplete neural signs.

(a) Compression and occlusion of the spinal arterial system at the time of injury by the upper margin of the lower vertebrae or by the extruded or dispersed bone in compression fractures. From our observation this arterial compression is not a continuing feature, not being once demonstrated in a series of over 36 post-mortem studies.

(b) By damage to the medullary or spinal vessels at the seat of injury to bone.

(c) By subsequent thrombosis at the site of injury.

(d) By the anchorage of the cord via the dentate liagaments and the inability of the cord and vessels to avoid trauma at the moment of impact.

For all these causal factors pathological evidence has now been produced by authors such as Wolman (I964), Schneider et al. (I958), Freeman and Russell (I955). Most authors agree, however, that rarely are these shown to have any continuity except for thrombosis with the passage of time. In our own specimens, examined at death after varying periods of time, continuing compression to the vascular pattern of the cord has not been demonstrated.

II. Crushing of the Cord and Meninges. This pathological picture is always associated with a severe flexion and rotation or extension rotation injury 
of the column (figs. 3 and 4). In a series of 30 cases of severe flexion and rotation injuries seen in Australia (in Victoria and Western Australia), I8 proved to be complete, whilst $\mathrm{I} 2$ were incomplete. The cord is crushed between two bony jaws, in either case these jaws being a lamina and the upper or lower margin of an adjacent vertebral body. These injuries are more often complete (see clinical series

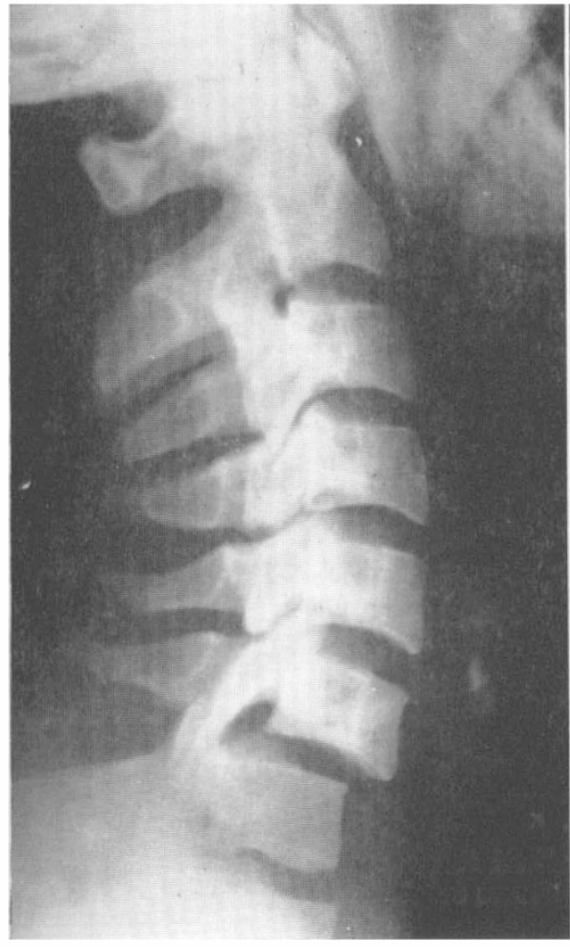

FIG. 3

Severe dislocation.

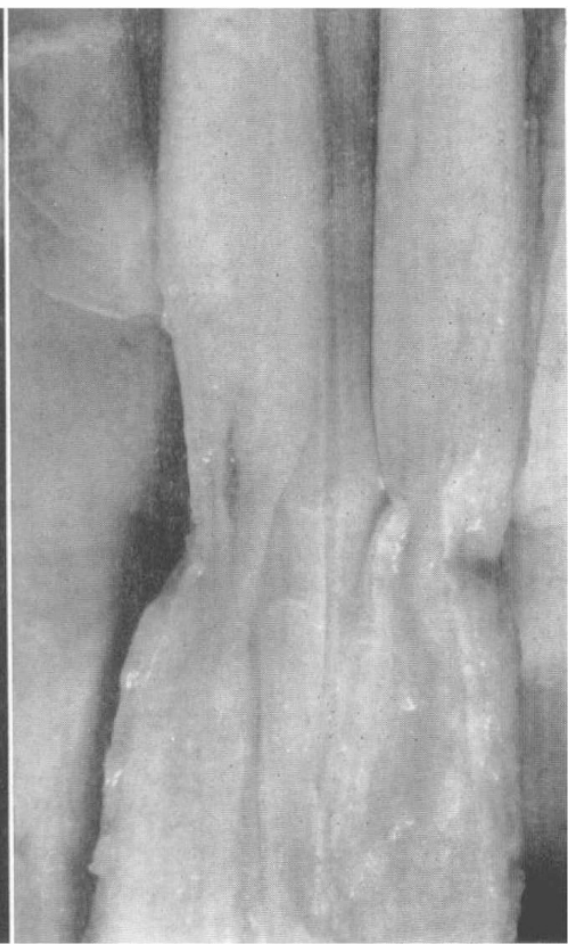

FIG. 4

Crushing of cord. Note length of lesion not explainable by one factor, involves stretching.

above) from the beginning; the neural tissue being pulped and squeezed apart in a peculiar $\mathrm{V}$ or cone-shaped fashion. Such a blunt injury will ultimately heal only by dense impenetrable neuroglial and fibrous tissue which may extend over a number of vertebral segments.

III. Longitudinal Features. In many cord injuries there are combinations of both of the above types, vascular and direct damage. In addition however, many cases coming to autopsy within a few days of injury show a much longer segment of the cord involved than is expected by just vascular disturbances or by compression and crushing alone (fig. 5). The extent of early colliquative necrosis can only be explained by consideration of another factor acting in combination with the above. This length of lesion is, I believe, a manifestation of direct stretching force as discussed in a previous communication (Bedbrook, I963) as 
well as the already discussed pathogenic forces. For example, one must be reminded that most injuries occur at the cervical enlargement of lumbar enlargement where constant large vessels enter via the nerve roots to reinforce the spinal arterial system. Here, damage to the arterial system may be dominant. Longitudinal

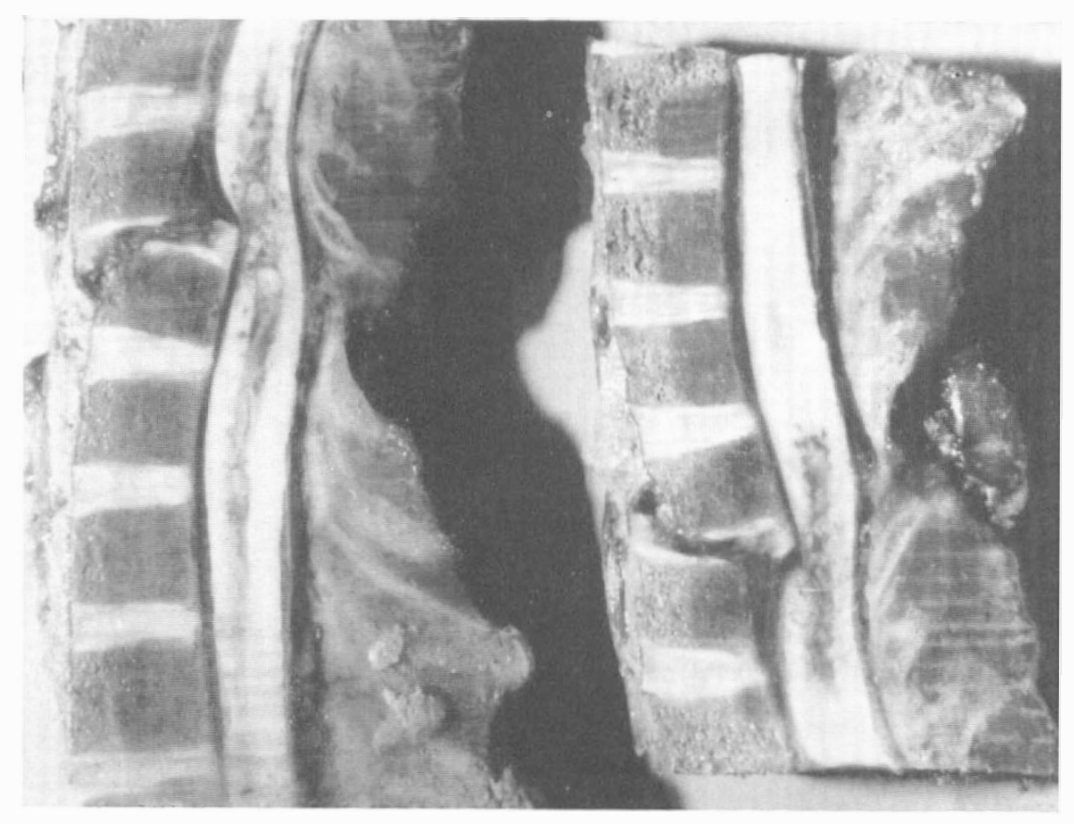

FIG. 5

Unilateral locked facet dislocation. Longitudinal features of haematomyelia, crushing, extra-dural haemorrhages and shows original compression.

stretching and blunt division of the cord and nerve roots are the commonest methods of observed damage. Cauda equina injuries exhibit a pattern of ragged injury at both operative and post-mortem studies. The following changes are seen:

I. Normal nerve roots.

2. Divided and shredded nerve roots.

3. Nerve roots showing Wallerian changes.

4. Nerve roots showing colliquative necrosis.

5. Apparently elongated nerve roots.

The cauda equina, as distinct from the cord, has not been observed in our dissected material to be affected by continuing compression (which is relievable by surgery). Jefferson noted such rarity of compression in spinal cord injuries as far back as I928. Wolman (1964) in his recent review agrees with its rarity. Sharp division of the cord and nerve roots in our community is a rare injury. Others, however, have more experience in this particular type. Even here, however, the cord as well as being injured by direct trauma can be so by vascular injury or in a contra-coup 
manner. Rarely has such sharp division led to the surgeon being able to repair such injuries. Windle (I955) and his colleagues, however, discuss such a case in more detail.

IV. Peri-Neural Changes. Extra-dural and subarachnoid haemorrhage are concomitant problems. They are rarely seen alone. The former always extends for some distance over the surface of the dural membrane and plays a part in the ultimate periduralfibrosis that is so common in chronic phases (fig. 6). The latter causes irritation of the meninges and is responsible for the eventual surface staining seen at later stages.

\section{BONY PATTERNS}

The bony pathological characters are well documented by many, e.g. Nicol (1949), Beatson (1963), Barnes (I948), Holdsworth (I963), Durbin (I957), Bedbrook (in press). However, a brief comment on a few features will help to clarify this subject:

(a) The neural canal is rarely if ever, after adequate conservative therapy, seen to still be seriously reduced in diameter. Reduction up to 50 per cent. is needed before most spinal cords or cauda equinae are in danger of circular compression. Bony compression, whilst a real force at the time of injury, is regularly reduced before the surgeon encounters the patient. Pathological studies by a number of authors show this to be an extremely rare continuing force during and with adequate conservative therapy. One case of further bone compression has been seen in our own series, where indeed this occurred after early surgery which had not relieved the patient of his paraplegia and where an ultimate exostosis growing in from the operation area irritated an incomplete cord lesion (fig. 7).

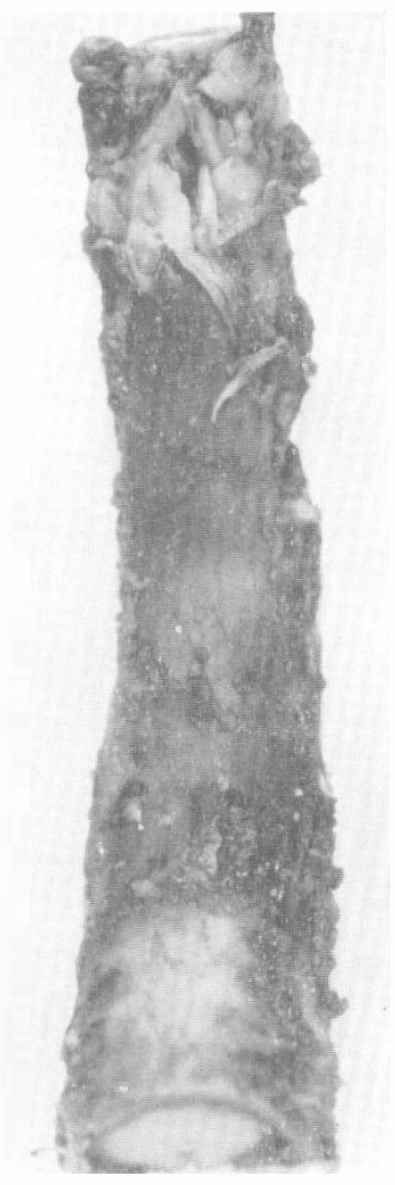

FIG. 6

Extensive extra-dural haemorrhage.

(b) Vertical compression fractures, whilst they cause dispersion of bony fragments into the neural canal causing direct and indirect, e.g. vascular damage, have again not been shown to be a type of fracture where continuing bony compression exists after the moment of injury and subsequent to good conservative therapy.

(c) Unilateral fracture dislocations proving irreducible at the time of injury by conservative means are usually stable and their open reduction should be needed only rarely. A series of 44 such cases treated in Australia showed that 34 were associated with incomplete and transitory cord lesions, while ro were associated 
with severe and complete lesions. The problem of clinical judgment associated with such are well illustrated in the following case.

This is a male aged 35 with a unilateral fracture dislocation of $\mathrm{C}_{5}$ on $\mathrm{C} 6$ with bilateral lower motor neurone paralysis of $\mathrm{C}_{5}$. This rapidly disappeared on traction which failed to reduce the dislocation. General anaesthesia and a careful re-positioning procedure failed also to reduce this dislocation. Open reduction in the presence of this type of injury was considered unnecessary (see Beatson, 1963). Six weeks later when traction was removed, however, lower motor neurone paresis recurred bilaterally in $\mathrm{C}_{5}$ and unilaterally in the left upper limb in C6, 7 and 8, all within 24 hours. No compression could be demonstrated by radiology and manometry, and as three nerve roots were involved, a vascular cause for the paresis was diagnosed. Operation was deferred and then discarded.

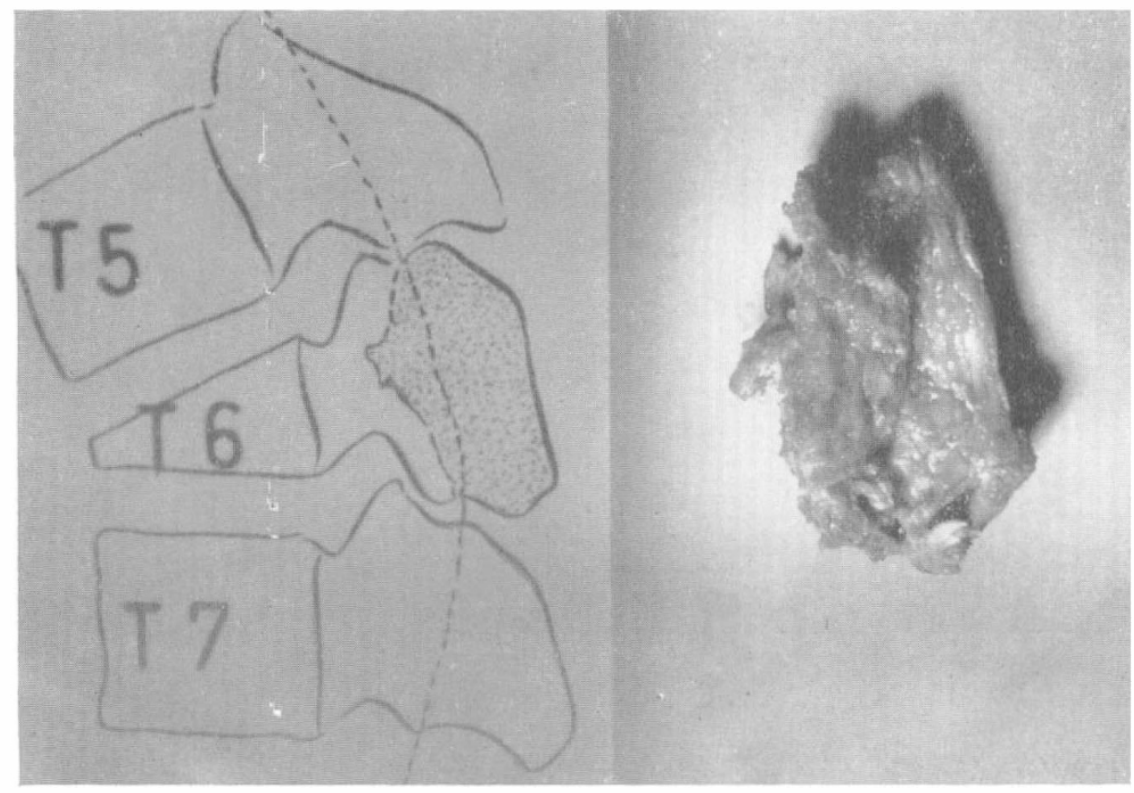

FIG. 7

Exostosis after old laminectomy causing irritation and pressure on an already damaged cord.

Today, this man's spinal fracture-dislocation has united and he has been left with moderate $\mathrm{C}_{7}-\mathrm{C} 8$ paresis in the left upper limb, which can be rectified by tendon transfers. With a knowledge of this natural history and pathology, open surgery and reduction in the early stages may have been successful, but I believe there was a great chance of serious deterioration by vascular interference as there was indeed at the time of the later relapse, and thus in the absence of further compression, surgery was discarded.

(d) Complete disc extrusions causing compression do occur. Pathologically, such cases come to post-mortem rarely and then some time after the accident. Clinically, cases are extremely rare and, I believe, difficult to diagnose. Such protrusions in recorded cases are frequently associated with many of the other manifestations, both neural and bony. 
FINAL PATTERNS

Pathological processes take time to become manifest. Time also shows the natural history of such a process. Examination of specimens after some days have elapsed show that areas of softening usually extending over more than one segment occur in cords that at operation were reported as macroscopically normal. Many surgeons have reported on this sequence. This colliquative necrosis results both from the direct injury and the indirect effects of stretching with lack of blood supply. This latter may become apparent only after a few days, when manifestations of spinal cord dysfunction are late in onset. Such late onset cases must always have spinal manometry to exclude the occasional extra-dural haemorrhage causing further cord compression.

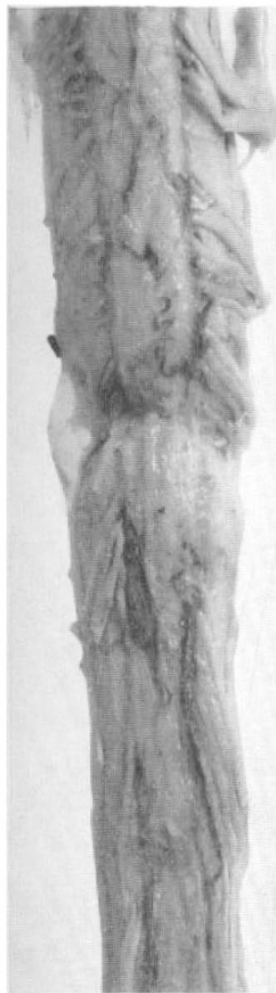

FIG. 8

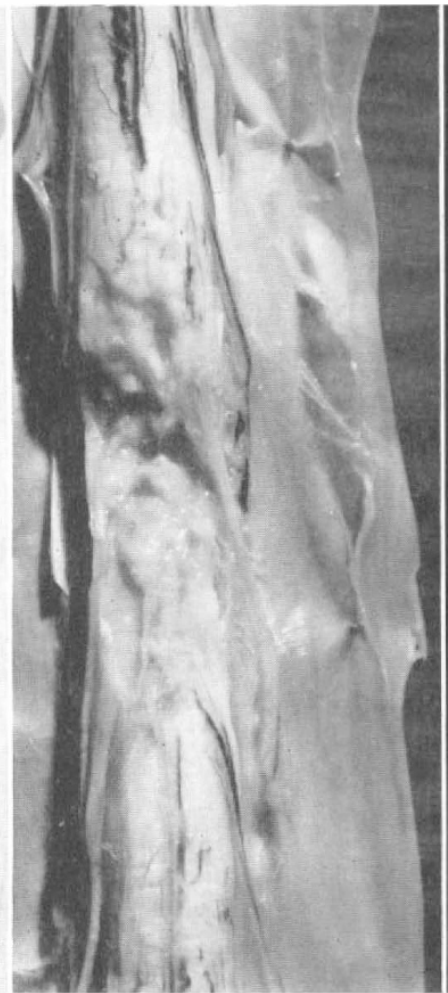

FIG. $9 a$

Crushed cord.

$$
\text { Ragged cyst. }
$$

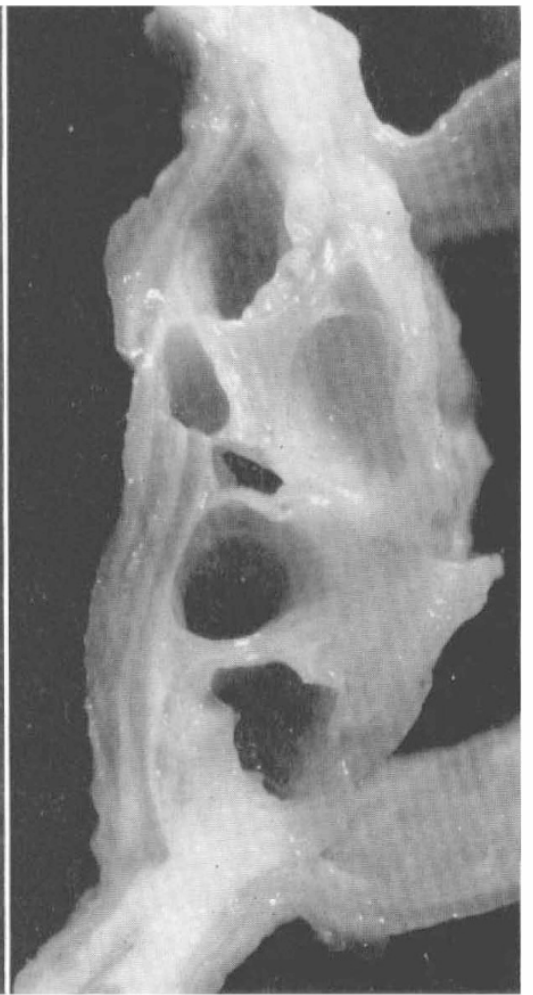

Fig. $9 b$ Smooth cyst.

In cases where haematomyelia has occurred, absorption of the blood leaves early cyst formation whilst inevitably neuroglial proliferation will cause scarring and contracture.

As time progresses the damaged cord tissue is slowly replaced by scar. In our specimens three pictures emerged:

(a) A crushed cord pattern (fig. 8).

(b) Ragged cysts and finally smooth walled cysts (figs. 9a and b). 
(c) Dense peridural and perineural scarring into which the cord disappears above and reappears below. If neural tissue has survived the early onslaught of trauma it may not now survive the final constriction by avascular scar tissue, nor at times does the already affected vascular pattern.

\section{APPLICATIONS TO CLINICAL MANAGEMENT}

With these pathological pictures in mind, how then should the surgeon approach the problem of therapy? Experience throughout the world shows that the majority of injuries to the spinal cord and cauda equina will be caused by extreme trauma of a ragged type manifested and expressed by forces in different directions. Such trauma causing injury elsewhere in the body leaves a trail of destruction which surgical conservatism (operative or non-operative) can minimise but which surgical attack can easily make worse, e.g. the internal fixation of badly comminuted fractures in severely traumatised limbs. Compression as a continuing cause of neural signs and symptoms has been shown to be a rarity that must be searched for diligently and relieved. If such has been present for more than a few hours relief rarely improves the patient. Spinal block has not proved a constant indication for surgery.

Thus the most satisfactory way of minimising the effects of this trauma will be to carefully and conservatively reduce the bony trauma into adequate position and thus allow the cord the freedom of the canal to pass through the stages of shock, oedema, sparing, absorption of debris, and neuroglial proliferation. All undue movement must be stopped.

Clinically it can be shown that adequate nursing maintains this position just as satisfactorily without internal fixation as with.

In the lumbar column all fractures and fracture dislocations rapidly stabilise and in almost 100 per cent of cases bony fusion rapidly occurs. In this part of the column a series of I68 cases have now been studied with only two having non-union causing pain.

With the knowledge that continuing compression is a rarity pathologically, the risk of further damage to the cord and cauda equina is materially less in conservatively treated cases than has been thought by some authors. In not one of the conservatively treated cases could evidence be found initially or later that led me to the conclusion that by conservative means further deterioration had occurred. In fact, I found the opposite. Two cases operatively treated some years ago had deteriorated temporarily; others have also reported similar cases.

In the cervical column 85 cases were treated conservatively in Western Australia, 60 were in the flexion rotation group commonly thought unstable. Of these 60,22 were caused by vertical compression; these 22 all healed by bony union or pseudarthrosis. I6 cases were severe fracture-dislocations-only one proved unstable after three months and of the other 22 with partial dislocations, four were unstable after three months. Thus only 9.0 per cent. of the total were proved finally unstable, so that instability cannot be used as an absolute indication for surgery. Of the total 85 cases, seven were of that type where X-ray suggests dislocation unassociated with fracture. Of these only one was unstable after three 
months' conservative therapy. Once again a very small instability rate in a type of injury considered by some to be an absolute indication for surgery (Table I).

In a total series of such fractures with cord damage treated in two spinal injuries services in Australia, I80 cases were suitable for study. Of these only I 3 were truly unstable -7 per cent. of the total. This shows that the natural history is toward stability in all types.

\section{TABLE I}

Skeletal Pathological Survey in 85 Quadriparetics treated without Early Surgery

\begin{tabular}{|c|c|c|c|c|c|}
\hline Pathogenesis & $\begin{array}{c}\text { Death } \\
\text { before } \\
\text { patho- } \\
\text { logy } \\
\text { static }\end{array}$ & $\begin{array}{c}\text { Anterior bony } \\
\text { bar and body } \\
\text { Fusion }\end{array}$ & $\begin{array}{l}\text { 'Soft tissue' } \\
\text { union, but } \\
\text { stable }\end{array}$ & Unstable & Totals \\
\hline \multicolumn{6}{|l|}{ Flexion rotation injuries: } \\
\hline Less $\frac{1}{2}$ depth of body & 一 & I7 & I & 4 & 22 \\
\hline Greater $\frac{1}{2}$ depth of body & 3 & IO & 2 & I & I6 \\
\hline Compression Injuries & 0 & I9 & 3 & 0 & 22 \\
\hline Extension Injuries . & 2 & 2 & 7 & 0 & I I \\
\hline G.S.W. & 4 & I & 0 & 0 & 5 \\
\hline $\begin{array}{l}\text { Concussion (Transitory } \\
\text { cord lesion without } \\
\text { major bony damage) } \\
\text { Osteomyelitis after trauma }\end{array}$ & $\cdots$ & $\cdots$ & - & - & 8 \\
\hline $\begin{array}{l}\text { Osteomyelitis after trauma } \\
\text { (direct) }\end{array}$ & - & ..... & $\ldots$ & - & I \\
\hline & & & & & 85 \\
\hline
\end{tabular}

Another 28 cases had to be discarded from this section of the study for various reasons e.g. early operation, final result unknown, or uncertain early $\mathrm{X}$-rays did not give accurate classification.

Beatson (1963) sums up the position well when he says 'Operations are done because surgeons think spines may be unstable and thus it is safer to advise fusion. Perhaps this is safer for the surgeon, but is such open surgery safe for the patient?' Observations by many show that surgery can confer extra difficulties on patients:

(a) Cause or be associated with incomplete cases becoming complete:

(i) by interference with blood supply;

(ii) by allowing cord to prolapse through the laminectomy wound;

(iii) by causing or allowing infective myelitis.

(b) Internal fixation is not always possible or perfectly adequate even when performed under the best of conditions. Indeed, from our observations it is rarely more efficient than proper conservative methods in maintaining immobility.

(c) Is an extra traumatic episode for the patient to cope with, in that adrenal failure may cause death.

(d) Increased trauma to muscles. 
A particularly important clinico-pathological fact is that all the incomplete cases encountered in our spinal unit either improved or showed no clinical deterioration.

From a consideration of these facts, and the voluminous literature of observations by others, I have now reserved surgical interference in spinal cord injuries to those:

(a) No bony injury but complete paralysis with a block-extra-dural haemorrhage.

(b) Bony injury and incomplete quadriplegia or paraplegia becoming complete with a block-disc or haemorrhage, unfortunately often vascular. Surgery rarely helps.

(c) Gross bony displacement defying all attempts at conservative reduction.

(d) To late cases of truly unstable cervical fracture dislocations, but rarely if ever in the acute stage (see Table II).

\section{TABLE II}

Summary of Clinico-Pathological Correlation in Spinal Cord Injuries

\begin{tabular}{|c|c|c|c|}
\hline \multicolumn{2}{|c|}{ Pathological } & \multirow{2}{*}{ Clinical } & \multirow{2}{*}{ Treatment } \\
\hline Neuro & Bony & & \\
\hline $\begin{array}{l}\text { Haematomyelia or } \longrightarrow \\
\text { variation } \longrightarrow\end{array}$ & $\begin{array}{l}\text { Vertical compression } \\
\text { Flexion rotation } \\
\text { Extension rotation }\end{array}$ & $\begin{array}{l}\text { Anterior cord syn- } \\
\text { drome } \\
\text { Central cord syn- } \\
\text { drome } \\
\text { Lateral cord syn- } \\
\text { drome } \\
\text { Post. cord syndrome } \\
\text { Complete syndrome }\end{array}$ & $\begin{array}{l}\text { Conservative } \\
\text { (rarely open } \\
\text { reduction) }\end{array}$ \\
\hline $\begin{array}{l}\text { Longitudinal changes } \\
\text { (a) Necrosis } \\
\text { (b) Extra-dural } \\
\text { Haemorrhage } \\
\text { (c) Early cysts }\end{array}$ & $\begin{array}{l}3 \text { or more variable } \\
\text { vertebral fractures } \\
\text { of all above types }\end{array}$ & $\begin{array}{l}\text { Complete lumbar syn- } \\
\text { drome } \\
\text { Incomplete cervical } \\
\text { syndromes. } \\
\text { Extensive L.M.N. } \\
\text { lesion with U.M.N. } \\
\text { signs in lower limbs }\end{array}$ & Conservative \\
\hline $\begin{array}{l}\text { Continuing compression } \\
\text { by: } \\
\text { (a) Haemorrhage } \rightarrow \\
\text { (b) Bony } \longrightarrow\end{array}$ & $\begin{array}{l}\text { without above } \\
\text { as above }\end{array}$ & $\begin{array}{l}\text { Paresis becoming } \\
\text { complete }\end{array}$ & $\begin{array}{l}\text { Open decompression } \\
\text { Closed reduction }\end{array}$ \\
\hline Nil & $\begin{array}{l}\text { Unstable after } 3 \\
\text { months } \\
\text { non-union }\end{array}$ & Varies greatly & $\begin{array}{l}\text { Reduction } \\
\text { Grafting }\end{array}$ \\
\hline $\begin{array}{l}\text { Thrombosis of cord } \\
\text { vessels } \\
\text { Arterial insufficiency }\end{array}$ & $\begin{array}{l}\text { Any of the bony } \\
\text { problems }\end{array}$ & $\begin{array}{l}\text { Paraplegia late onset } \\
\text { without block }\end{array}$ & Conservative \\
\hline
\end{tabular}


Some will say that it is difficult to differentiate compression and destruction: therefore operate. This, I feel, was true before we had the sad but nevertheless accurate facts of pathology. Now we can with some confidence pursue the pathway of truth that will ultimately lead to a happier solution to these disabling conditions.

Much remains to be sorted out in considering the pathology of spinal cord trauma:

(a) the significance of manometry;

(b) the exact mechanism of injury, particularly stretching;

$(\dot{c})$ the use of the term concussion;

(d) the role of the dentate ligaments;

(e) the vascular disturbances;

$(f)$ does repair and regeneration ever occur in the absence of gliosis?

These are the problems needing further study.

\section{SUMMARY}

Pathological principles governing early management of spinal cord trauma are:

I. The anatomical features of capacity, blood supply, and spinal cord structure.

2. The mechanisms by which the trauma is caused: flexion, extension and rotation, together with crushing, stretching and concussion.

3. The neural pathological pictures which emerge

(i) Haematomyelia of the cord, with many manifestations caused by direct compression and direct interference with blood supply.

(ii) Gross crushing of the cord.

(iii) Subarachnoid and extra-dural haemorrhage.

(iv) Longitudinal manifestations of stretching and colliquative necrosis.

4. The bony patterns:

(i) The importance of the integrity of the neural canal after conservative management.

(ii) The absence of continuing bony compression.

In the later stages the final patterns that emerge are:

(i) Gross crushing.

(ii) Cysts.

(iii) Peri-neural and peri-dural fibrosis.

Applying these pathological principles, the author believes that a rational method of conservative treatment is, under most circumstances, the only method 
of management to be considered and explains the almost universal rejection of operative interference, since such interference can do little to affect the pathological state which has existed since the time of injury. Clinico-pathological facts which emerge are:

(a) That movement of the fracture site is minimal with proper nursing.

(b) Only a small percentage (7 per cent.) of a potentially unstable group of fractures in the cervical spine prove to be so after adequate management.

(c) Non-union is a rarity in lumbo-dorsal fractures and stability occurs early after the time of injury.

\section{REFERENCES}

BARNes, R. (1948), f. Bone E ft Surg. 30B, 234.

Beatson, T. R. (1963). F. Bone E ft Surg. 45B, 2 I.

BEDBROOK, G. M. (1963). Paraplegia, I, 215.

Durbin, F. C. (I957). f. Bone E ft Surg. 39B, 23.

FreEMAN, L. W. \& Russell, J. R. (1955). F. Neurosurg. I2, 584.

Gillilan, L. A., Crosby, E., Humphrey, T. \& Laver, E. (I962). Correlative Anatomy of the Nervous System, Chap. 9.

Holdsworth, F. (1963). F. Bone \& ft Surg. 45B, 6.

Hughes, J. T. (1964). Paraplegia, 2, 2.

Jefferson, G. (1928). Proc. R. Soc. Med. $21,625$.

Nicol, E. A. (1949). F. Bone E Ft Surg. 31 B, 376.

SCARFF, J. E. (Revised 1960). In: Injuries of the Brain and Spinal Cord and their Coverings. Edit. S. Brock, 4th ed., p. 530. London: Cassell.

SChNeIDer, R. C., CHERry, G. \& PANTEK, H. (I954). F. Neurosurg. I I, 546.

Schneider, R. C., Thompson, J. M. \& Bebin, J. T. (1958). F. Neurol. Psychiat. 2i , 2 I6.

WINDLE, W. F. (1955). Regeneration in the Central Nervous System, p. 24I. Springfield, Ill: C. C. Thomas.

Wolman, L. (1964). Paraplegia, I, 233. 